\title{
Mass Performance of Adapted Physical Activity: A "Population Strategy to Prevent Frailty": Setting-Up and Running the Service-8 Years of Experience
}

\author{
Piastra $\mathrm{G}^{1}$, Lucarini $\mathrm{S}^{1}$, Cavagnaro $\mathrm{P}^{1}$, Ganzarolli $\mathrm{L}^{2}$, Vaccaro $\mathrm{G}^{2}$ and Gallamini $\mathbf{M}^{2,3 *}$ \\ ${ }^{1}$ Liguria Region Public Health Service-ASL4Chiavarese, Chiavari, Italy \\ ${ }^{2}$ Ben-Essere ASD-Non Professional Sport Association, Italy \\ ${ }^{3}$ Freelance Researcher-Member of the It. Society of Clinical Movement Analysis (SIAMOC), Italy
}

Submission: March 22, 2017; Published: April 27, 2017

*Corresponding author: Gallamini M, Ben-EssereASD-Non Professional Sport Association, Italy. Tel: 39-335 5683177

Email: michele.gallamini@fastwebnet.it

\begin{abstract}
Lack of physical activity has been postulated to be the cause of a significant loss of healthy life expectancy and in much greater costs, both for the National Health Service and for the individual. On the other side, the beneficial effects of Adapted Physical Activities have been demonstrated in many of the pathologies prevalent among older persons. Our experience, arising from a test performed 8 years ago, has demonstrated both the beneficial effects on the participants and the substantial reduction of costs for the Health Service. Nowadays, more than 2,500 senior citizens from the area covered by our Local Health Service take part in several Physical Activity courses that include both Adapted Physical Activity and fitness programs. The courses are managed by a private, nonprofit entity under the supervision of the Local Health Service and have involved also the local Social Services and the Municipalities. By all accounts the approach is successful and worth applying on a larger scale. The applied criteria and organization are described and guidelines proposed for further development.
\end{abstract}

Keywords: Frailty prevention, Adapted physical activity, Primary care, Population strategy, Risk of fall prevention

Abbreviations: APA: Adapted Physical Activity; APE: Adapted Physical Education; ASL: Italian Local Health Service; GDS: Geriatric Depression Scale; GP: General Practitioner; HSIC: Health \& Social Care Information Centre; NHS: National Health Service; RM: Roland Morris Questionnaire

\section{Introduction}

In 2012 the Health \& Social Care Information Centre (HSIC) published the initial results of the Health Survey for England on Physical Activities in the UK. The document provides a quick review of the effects of inactivity and on the beneficial effects of Physical Activity [1]." Lack of physical activity is the fourth most important risk factor worldwide for chronic, no communicable diseases, after tobacco use, raised blood pressure and hyperglycemia (raised blood sugar) [2] In the UK, inactivity has been estimated to cause 3\% of disability adjusted years of life lost in 2002; this represents a direct cost to the NHS of E1.06billion, with indirect costs to society bringing this cost to a total of E8.2billion. Inactivity is particularly important in some groups. For example, inactivity was estimated in 2011 to account for at least $20 \%$ of the excess heart disease deaths seen in the South Asian community in Britain.
Physical inactivity contributes to: cardiovascular disease, particularly ischaemic heart disease and stroke, cancer of the colon and breast; psychological distress and depression; and dementia as well as being a major cause of obesity and diabetes [3-11]. Regular physical activity reduces all-cause and cardiovascular mortality, even among those with an otherwise high cardiovascular risk profile or with established cardiovascular disease; reduces the incidence of ischaemic heart disease and stroke; reduces longterm blood pressure in both those with raised and with normal blood pressure; improves cognitive function in older people with and without existing impairment; reduces anxiety; and improves mental well being [12-22].

At the core of the diffusion of Physical Activity lies the approach to a "Population Strategy" as defined by Rose in 1985 [23]. In layman's words, significant improvements in population 
health indicators should be achieved by the adoption of a healthier lifestyle.

However, a healthier lifestyle cannot be limited to increasing the quantity or quality of physical activities:

- $\quad$ To reduce the prevalence of adult obesity [24], a major concern for preventive medicine, and to tackle the increase of osteoporosis [25], the control of food intake, in both quality quantity is of the utmost importance or

- $\quad$ To reduce the Risk-Of-Fall [26], besides some specific Physical Activity aimed to balance, the adaptation of living space is generally required.

Furthermore, the complex interactions between mood and health suggest that a specific attention should be given to the social aspects of the daily life of an elderly person [27-29].

\section{APA: A medical intervention?}

Given the broader scope involved in the concept of "healthy lifestyle" the question that arises immediately is whether Physical Activity, at least that proposed to senior citizens, should be considered as a medical intervention or not [30,31]. The fact of the matter is that the link between Physical Activity and Health was born in Medicine as an adjunct to the rehabilitation process [32,33] and/or as a tool for preventive medicine [34-37]. The proposal of a healthier lifestyle within a true "population strategy" should include Physical Activity as well as Social Inclusion Initiatives and instructions on how to upgrade daily living activities (improvements in living spaces/facilities, nutritional education, recreational activities, etc.) The program begins to shift towards a Social approach, under Medical advice. Life expectancy is now rapidly increased to the point that, in the Liguria Region of Italy, the life expectancy for a 65 year old person is about 19 (Males) and 23 (Females) years!.

Although the most effective way to extend the healthy life span would be to adopt a healthier lifestyle early in life, there is still time to intervene in the case of senior citizens aged over 65. At this age, however, there is a high prevalence of "frail" or "prefrail" individuals, [38] according to the prevailing definition of these terms [39-42]. Very often, these persons carry on a "normal" life with some compensation of slight pathological conditions (mild atherosclerosis, compensated hypertension.... etc). These persons can however perform also Physical Activities-some even specifically recommended-although with some limitations [43].

Based on these concepts, Adapted Physical Activity was developed such that it could also be proposed to pre-frail individuals. The main concept is the execution of simple exercises linked to a specific task, at a level of intensity level suited to the specific condition of each individual. As stated by Titze \& Martin in 1997 "In contrast to the previous assumption that only fairly high-intensity sporting exercise undertaken over a minimum period of $20 \mathrm{~min}$ produces health-related benefits, recent studies have shown that even everyday activities (climbing stairs, brisk walking and cycling) can have a beneficial effect on health, particularly in those who take little exercise. So now the recommendation is: exercise of moderate intensity lasting $30 \mathrm{~min}$ at least 5 times a week, corresponding to an energy consumption of about $150 \mathrm{kcal} /$ day or $1000 \mathrm{kcal} /$ week" [44].

Since then growing evidence has been produced in support of APA effectiveness with respect to specific themes such as: Osteoporosis, Back Pain, Flexed Posture, Sarcopenia, Eating Disorders, Balance and Motor Control, Diabetes, Parkinson Disease, Multiple Sclerosis, Acute Stroke, Cardiovascular Diseases, Breast Cancer, Fibromyalgia, Chronic Fatigue Syndrome [45-61]. At the same time, a generic effectiveness of APA in healthy aging has been observed [62-66]. In addition to a very comprehensive definition of Adapted Physical Education (APE), [67] there are also bibliographic references to the more specific Adapted Physical Activities as a Health-Oriented practice [68], different from the traditional sickness-oriented practice and more closely related to the social and environmental assistive activities.

\section{The role of the public health service}

Given that Physical Activity, as well as favoring healthy aging, has a specific role in the functional recovery and in the prevention of specific diseases, [69] we submit that the main sponsor of the Physical Activities promotion should be the General Practitioner to whom the primary prevention of illness is entrusted. It cannot entail true "Prescription", otherwise the Physical Activity would become a Medical Tool, but there should be an active, hopefully bi-directional, link between the GP and the Physical Activity Instructor [70]. There is a lively debate on the subject, [71] but in spite of the name- whether it should be a Prescription or Counseling or Advice [72,73] the main actor should be the GP who should be made aware of both benefits and general prescription criteria [74]. Furthermore, in Italy, Government Authorities have recommended that APA should be applied wherever feasible as a tool to promote a healthier lifestyle, [75] although without the involvement of medical professionals and at no additional costs for the National Health Service.

However, we submit that the referenced governmental indication should at least be discussed.

- The simple issue is why, how and on what ground should the GP- under contract to the National Health Servicebe involved in prescribing, suggesting or advising APA and shouldering the relative responsibility?

- A more complex issue is the reference to additional cost. Several studies have shown that preventive medicine- and APA can be included in this categoryin the medium term, leads to a significant reduction of health related public costs [76]. This is confirmed 
by our experience: a preliminary study analyzing NHS services expenditures for individuals following our APA program has demonstrated a substantial abatement of drug prescriptions and accesses to out-patient services (diagnostics, physiotherapy) [77].

A deeper investigation is now underway on a larger population, seeking a possible correlation between this reduction and the frequency of attendance at APA sessions. If the formal requirement is constant cost, the reduction afforded by APA could well be supported by a certain NHS investment, if nothing else, at least to support the involvement of GPs and to set up an internet-based network between GPs, local NHS management and APA management. In any case, to return to the role of the GP, they can at least be asked to recommend if not to prescribe APA.

\section{Discussion-Our Experience}

\section{The test phase}

In 2008 the ASL 4 Chiavarese started an experimental APA project specific for Low-Back-Pain, Dorsal Kyphosis and Balance Rehabilitation. After nearly 6 months of twice weekly group APA exercising (one hour per session) encouraging results were observed [78]. The beneficial effects were measured in terms of pain reduction (over $85 \%$ declared a significant improvement), of reduction of medical assistance needs (drug consumption or Rx Diagnostics or Clinical examinations- 80\%) and quality of life enhancement (GDS and RM). The program was successful and the participants passed their satisfaction "down the grapevine". Based on individual and GPs' requests, the population accessing APA courses has constantly grown to over 2,500 persons (March 2016) (Figure $1 \& 2$ ).

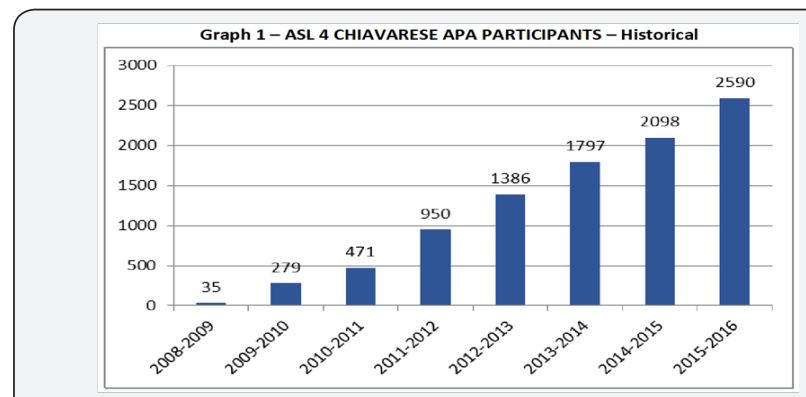

Figure 1: ASL 4 Chiavarese APA participants - Historical.

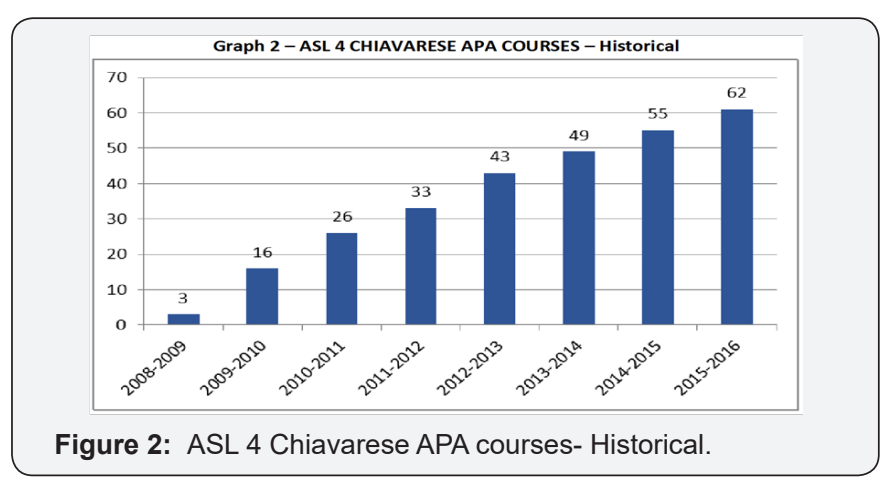

\section{Logistics and organization}

The effort required to find appropriate spaces in the ASL4 territory, which covers the valleys on the East coast of Liguria, was rather hard but successful: there are now 62 courses in 13 Municipalities where rooms capable of accommodating groups of 20 persons performing APA exercises were successfully found and set up for the purpose. The choice of setting up exercise rooms close to the living areas was crucial to the success of the program: the geological characteristics of the ASL4 area with mountains and deep valleys with a rocky seafront make travelling time-consuming and tiring.

An effort was made to set-up regular procedures and appropriate software tools:

- $\quad$ To enroll the participants

- To integrate the instrumental tests, the self-administered questionnaires, the medical information available from different sources

- To standardize the formal procedures.

Thanks to the above it has been possible to monitor course attendance and participants' health conditions (Figure 3).

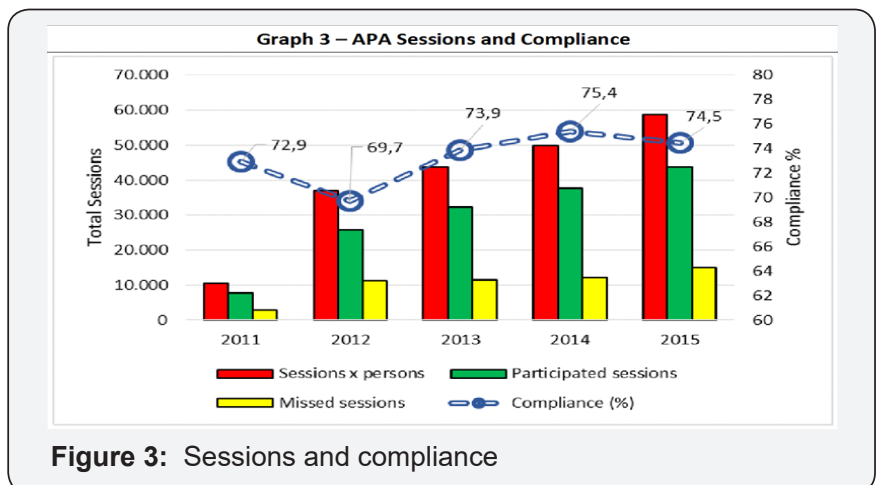

It is worth noting the high level of participation, which may be considered a sort of "customer satisfaction" index but, more importantly, a sign of the participants' awareness of APA as a new lifestyle.

Furthermore, instructors have reported the growth of "Social Inclusion" indicators within each APA Group: participants started sharing transportation and some social events. This phenomenon is one of the hoped-for side effects of the APA courses and is perhaps only to be expected [79].

\section{Trainers, management and costs}

The ASL4 Chiavarese selected and gave specific education to the trainers (motor sciences university graduates and/or physiotherapists with APA specialist qualifications), performed the health assessment according to standard rules and monitored activity performance.

The Instructors are on the payroll of "Ben-Essere" Non Professional Sport Association. The association levies a quarterly 
participation fee of 50 Euros. This income pays for the insurance, gym-related expenses, legal obligations and compensation of trainers: in the budget of Ben-Essere some allowances are made for further investments. However, the fee can be reduced according to the person's income upon agreement with the Social Services.

Table 1: APA courses Exercises.

\section{Main Theme}

\section{Session Program}

2 weekly sessions, $1 \mathrm{hr}$ each

Objective: posture, mobility, reinforcement, stretching, respiration, balance, relaxation. Each Session is subdivided into three phases:

\begin{tabular}{|c|c|c|}
\hline $\begin{array}{c}\text { Back-Pain or } \\
\text { kyphosis }\end{array}$ & & $\begin{array}{l}\text { phases: } \\
\text { Standing (10-15'): cardiovascular activation, shoulder and coxo-femoral joints mobilization, lower limbs reinforcement. } \\
\text { Sitting (10-15'): neck and shoulders mobilization. } \\
\text { On the Ground (5-30') spine mobilization, abdominal muscles reinforcement, gluteal and spine extensor muscles } \\
\text { reinforcement, spine stretching, ischiocrural and psoas muscle reinforcement, self-stretching and final relaxation. }\end{array}$ \\
\hline Balance & $\begin{array}{l}\text { a. } \\
\text { b. } \\
\text { c. } \\
\text { d. }\end{array}$ & $\begin{array}{l}1 \text { weekly session (additional to other courses) lasting } 90^{\prime} \\
\text { Objective: proprioception and balance control training Each session is subdivided four phases: } \\
\text { A warming-up sequence (10-15'). } \\
\text { A specific Qi-Gong (ZhiNeng Qi Gong, basic) sequence (20-30'). } \\
\text { A specific Tai-Chi (primary Taijiquan Wu style } 18 \text { figures) sequence (30-40'). } \\
\text { A respiration and relaxation sequence (10-15'). }\end{array}$ \\
\hline
\end{tabular}

2 weekly sessions, 1 hr each

Objective: increase of muscular strength and tone to improve posture and motor control for sarcopenia and Risk-Of-

Fall increase of muscular strength and tone to improve posture and motor control for sarcopenia and Risk-Of-Fall Each session is subdivided into three phases:

Muscle Mass a. Reinforcement b. b.

Standing (15') warming up and motor coordination exercises.

Standing/On-the-Ground (30') muscle tonification at low/medium intensity for different muscular districts (primarily abdominal and both lower and upper limbs) with low weight loads (0.5, 1.0 or $1.5 \mathrm{Kg})$.

Defatigation (15') and relaxation/stretching of the muscle systems with specific exercises (respiration and stretching)

(The exercises are specifically selected among a list of 70: 15 for warming-up, 35 for muscle tonification, 20 for stretching, respiration and relaxation).

\section{2 weekly sessions, $1 \mathrm{hr}$ each}

Nordic $\quad$ Objective: group motor activity, mostly aerobic, targeting primarily cardiovascular, dis-metabolic or respiratory pathologies. The walking standard session includes a mostly aerobic walk with the specific style (sticks) followed by exercises to improve strength, balance, motor coordination/control.

2 weekly sessions, $1 \mathrm{hr}$ each (summertime, either in the morning or in late afternoon)

Objective: Chronic pain, muscle tone, muscle mass, proprioception. This special course exploits the well-known positive effects of sea water (chronic pain, microcirculation, lymphatic drainage by the wave induced pulsating massage), passive load of water

\begin{tabular}{l|l} 
APA-Sea & on the limb movement which is beneficial for muscle mass increase, wave induced unbalance to train proprioception and motor \\
control. The exposition to sunshine (in appropriate periods of the day) is beneficial to osteoporosis. The standard session includes
\end{tabular}

\begin{tabular}{l|l} 
APA-Sea & on the limb movement which is beneficial for muscle mass increase, wave induced unbalance to train proprioception and motor \\
control. The exposition to sunshine (in appropriate periods of the day) is beneficial to osteoporosis. The standard session includes
\end{tabular} a first phase on the beach with warming-up exercises, followed by a second phase in sea water with exercises to be performed in pairs to train joint mobility, muscle tone, body proprioception. Floating aids are used.

2 weekly sessions, $1 \mathrm{hr}$ each

Objective: Muscle reinforcement recommended for subjects willing to perform at medium intensity and/or for subjects to prevent sarcopenia. 16 working stations are used, 4 of which with Technogym Easyline machines. Each session is subdivided into four phases:

APA “Circuit" a. Warming up (12') Floor exercises mimicking the exercises that will be performed on the stations.

b. $\quad$ Core (32') two full turns are taken in all 16 stations for 30 " each followed by 30 " rest time and switching to the following station.

Group training (10') for lower limbs work out.

d. Final (5') stretching of the muscle district 42 exercises are currently selectively applied. 90 further exercises are presently being validated

\section{Peer-Reviewed course quality}

In accordance with general Quality Assurance criteria, the courses are monitored on the basis of specific checklists and through periodic "peer-review" inspections. Courses have to be performed in the same approved pattern and with the same sequences and timing for each specific course type.
The capability of providing Quality Assurance is of the utmost importance for the attendants, for the Health Service that is sponsoring the program and for the GPs that "prescribe" APA to their patients. For this purpose, a "peer review" approach has been established: trainers take turns in acting as inspectors of their peers, according to a specific checklist that covers all the aspects, ranging from quality of exercise and performances to 
the logistics of the training space and to the behaviour of the trainer under scrutiny. It is aimed to ensure the quality and homogeneity of APA activities for all the courses.

During the review

- 20 items are checked with regard to the logistics of the course with a max total score of 50 .

- 20 items are checked with regard to the session performance with a max total score of 50 . As an example of the process, in Graph 4 the results of the peer-review process, are reported for 14 trainers/facility in 2015 (Figure 4).

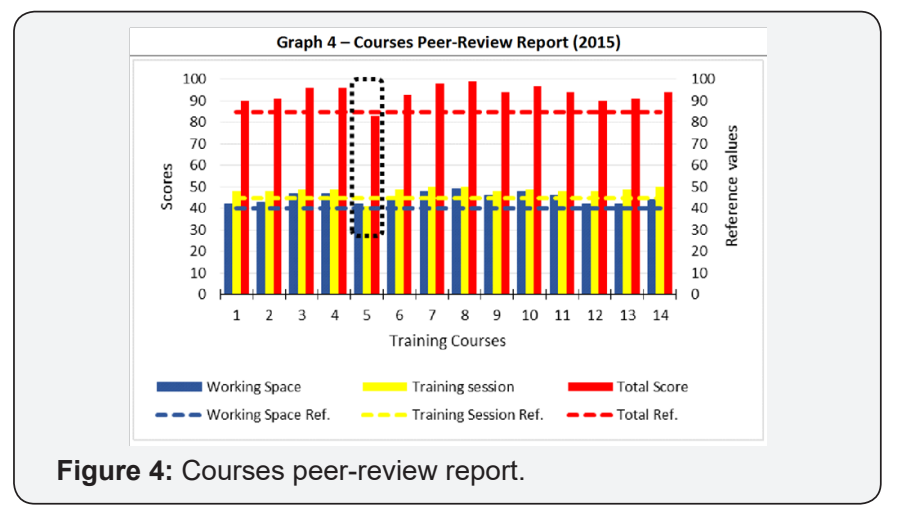

As can be seen, course \#5 was below acceptance limits and actions were undertaken to upgrade its overall quality. In the initial period the "peer review" approach has served also the purpose of ameliorating and standardizing the exercise programs. Data are recorded and monitored using the APA management Software tool. Efficiency indicators and attendance are recorded for each session. ASL Health Care Managers can monitor the courses by means of real time access to a specific on-line database.

\section{Effectiveness assessment}

Some effectiveness data are monitored by means of digitally scanned self-administered questionnaires derived from the most popular ones used for geriatric assessment: Activities of Daily Living (ADL)/ Instrumental Activities of Daily Living (IADL), Roland Morris, Geriatric Depression Scale (GDS), Falls Efficacy Scale (FES), Fear-Of-Falling, Minnesota Leisure Time Activity and questions related to lifestyle [80-85]. The results ("Checkup" software by MICROLOG SRL- Sassuolo (MO) are available on-line to the ASL Managers and to the Trainers.

\section{Functional performances assessment}

A set of instruments was procured thanks to the above budget allowances.

The tests are performed at least once a year on all the participants:

- $\quad$ Static Balance (Romberg Test), on Force Plate [86-87]

- $\quad$ SPO2-Saturimetry [88]
- Arterial Pressure

- $\quad$ Handgrip, (Hydraulic handgrip) $[89,90]$

- Arterial Stiffness, (Accelerated Photopletysmography) $[91,92]$

- Body mass composition, (Multifrequency segmental body impedance).

The set of recorded data generally confirm standard age/ sex related values. Deviations from average values are mostly associated with known pathologies. In some cases, however, it seems the observed deviations from average might indicate borderline individuals worth reporting to their GPs.

\section{Conclusion}

\section{Different courses}

As a natural evolution, besides the Back Pain groups, there are now Balance groups and also experimental Tai-Chi and Qi-Gong groups have been established. During the summer a Sea APA Group was run with wide participation and a Nordic Walking group started to practice along the hill paths of the areas. A group specifically aimed to increase the muscle mass has also been started.

\section{Participation}

As can be seen from Graph 3, the frequency of attendance levels out at $75 \%$, confirming the high level of compliance by the participants. The total participation of the over $65 \mathrm{~s}$ has reached the value of 1585 (March 2016) for a relative impact on the over 65 population related to ASL4 of 3.8\%. A significant shift has been observed in the motivation of persons enrolling in APA courses: besides the effect of the passage "down the grapevine" of the satisfaction of attendants, that in the beginning accounted for the vast majority of persons enrolling in APA courses, prescription by the GPs is increasing .

\section{Critical points and guidelines for improvement}

The experience should be rated successful, but it has demonstrated a few critical points:

I. An effort should be made to involve the GPs at a deeper level in enrolling their senior patients in APA courses.

II. The percentage of enrolled senior citizens is of just $3.8 \%$ of the total over 65 citizens referring to ASL4: a specific effort should be made to increase the diffusion of this service.

III. The participation of male subjects is very scarce: of the 1,585 over 65 subjects only $14,8 \%$ are males compared to $85.2 \%$ of females. This data is not satisfactory: it must be understood why the proposal is not appealing to senior males and a different strategy should be found and put in place.

IV. As stated in the Introduction to the present narrative Review, a healthier lifestyle should not be limited to an 
increase of physical activities. In close cooperation with the local Social Services, specific interventions should be made to ameliorate nutrition, social inclusion, and home safety.

V. Screening and functional assessment should be progressively enhanced and form the core of feedback to GPs prescribing APA to their patients.

VI. A correlation to Frailty according to the already mentioned standard and the possible extension of the functional assessment of the totality of the senior population would appear to have realistic growth prospects.

\section{Acknowledgement}

The authors wish to express their gratitude to the entire staff of Ben-Essere: the President Mario Franco Repetto and the D-EF Trainers:, Gloria Cesarale , Giada De Vincenzi, Micaela Gaetani, Giovanna Giosa, Giulio Katsiberis, Michela Letizia, Patrizia Liberti, Elisa Mazzini, Anna Isabella Mezzina, Ermanno Montepagano, Matteo Pinasco, Debora Porzio, Simona Rabitti, Giulia Rezzani, Valeria Rezzani, Matteo Ronchi, Luca Scevola, Nikla Stagnaro, Chiara Sturla.Their enthusiastic dedication made the set up and operation of the whole program possible.

\section{References}

1. WHO (2009) Is the adult population in England active enough? Initial results World Health Organization. Global health risks. Mortality and burden of disease attributable to selected major risks. WHO, Geneva, Switzerland.

2. Lee IM, Shiroma EJ, Lobelo F, Puska P, Blair SN, et al. (2012) Effect of physical inactivity on major non-communicable diseases worldwide: an analysis of burden of disease and life expectancy. Lancet 380(9838): 219-229.

3. Yusuf S, Hawken S, Ounpuu S, Dans T, Avezum A, et al. (2004) Effect of potentially modifiable risk factors associated with myocardial infarction in 52 countries (the INTERHEART study): case-contro study. Lancet 364(9438): 937-52.

4. Li J, Siegrist J (2012) Physical Activity and Risk of Cardiovascular Disease-A meta-analysis of prospective cohort studies. Int J Environ Res Public Health 9(2): 391-407.

5. Lee CD, Folsom AR, Blair SN (2003) Physical activity and stroke risk: a meta-analysis. Stroke 34(10): 2475-2481.

6. Hamer M, Stamatakis E, Steptoe A (2009) Dose-response relationship between physical activity and mental health: the Scottish Health Survey. Br J Sports Med 43(14): 1111-1114.

7. Ströhle A (2009) Physical activity, exercise, depression and anxiety disorders. J Neural Transm (Vienna) 116(6): 777-784.

8. Vogel T, Brechat PH, Leprêtre PM, Kaltenbach G, Berthel M, et al (2009) Health benefits of physical activity in older patients: a review. Int J Clin Pract 63(2): 303-320.

9. Stamatakis E, Hirani V, Rennie K (2009) Moderate-to-vigorous physical activity and sedentary behaviours in relation to body mass indexdefined and waist circumference-defined obesity. Br J Nutr 101(5): 765-773.

10. Demakakos P, Hamer M, Stamatakis E, Steptoe A (2010) Low-intensity physical activity is associated with reduced risk of incident type 2 diabetes in older adults: evidence from the English Longitudinal Study of Ageing. Diabetologia 53(9): 1877-1885.
11. Byberg L, Melhus H, Gedeborg R, Karl M (2009) Total mortality after changes in leisure time physical activity in 50 year old men: 35 year follow-up of population based cohort. Br J Sports Med 43(7): 482.

12. Hamer M, Stamatakis E (2012) Low-dose physical activity attenuates cardiovascular disease mortality in men and women with clustered metabolic risk factors. Circ Cardiovasc Qual Outcomes 5(4): 494-499.

13. Hamer M, Stamatakis E (2009) Physical activity and mortality in men and women with diagnosed cardiovascular disease. Eur J Cardiovasc Prev Rehabil 16(2): 156-160.

14. Hamer M, Stamatakis E (2009) Physical activity and risk of cardiovascular disease events: inflammatory and metabolic mechanisms. Med Sci Sports Exerc 41(6): 1206-1211.

15. Middleton LE, Corbett D, Brooks D, Sage MD, Macintosh BJ, et al. (2013) Physical activity in the prevention of ischemic stroke and improvement of outcomes: A narrative review. Neurosci Biobehav Rev 37(2): 133137.

16. Ishikawa TK, Ohta T, Tanaka H (2003) How much exercise is required to reduce blood pressure in essential hypertensives: a dose-response study. Am J Hypertens 16(8): 629-633.

17. Arroll B, Beaglehole R (1992) Does physical activity lower blood pressure: A critical review of the clinical trials. J Clin Epidemiol 45(5): 439-447.

18. Tseng CN, Gau BS, Lou MF (2011) The effectiveness of exercise on improving cognitive function in older people: a systematic review. J Nurs Res 19(20): 119-131.

19. Anderson E, Shivakumar G (2013) Effects of Exercise and Physical Activity on Anxiety. Front Psychiatry 4: 27.

20. Gauvin L, Rejeski WJ, Reboussin BA (2000) Contributions of acute bouts of vigorous physical activity to explaining diurnal variations in feeling states in active, middle-age women. Health Psychol 19(4): 365375 .

21. Windle G, Hughes D, Linck P, Russell I, Woods B (2010) Is exercise effective in promoting mental well-being in older age? A systematic review. Aging Ment Health 14(4): 652-669.

22. Rose G (1985) Sick individuals and sick populations. Int J Epidemiol 30(3): 427-432.

23. Penman AD, Johnson WD (2006) The changing shape of the body mass index distribution curve in the population: implications for public health policy to reduce the prevalence of adult obesity. Prev Chronic Dis 3(3): A74.

24. Correa RM, Schmidt Rio VJ, González JE, Rueda MB (2016) The Effects of Body Composition, Dietary Intake, and Physical Activity on Calcaneus Quantitative Ultrasound in Spanish Young Adults. Biol Res Nurs 18(4): 439-444.

25. Kovács E, Prókai L, Mészáros L, Gondos T (2013) Adapted physical activity is beneficial on balance, functional mobility, quality of life and fall risk in community-dwelling older women: a randomized singleblinded controlled trial. Eur J Phys Rehabil Med 49(3): 301-310.

26. Taheri TP, Moradinazar M, Najafi F (2016) Prevalence of depression and related social and physical factors amongst the Iranian elderly population in 2012. Geriatr Gerontol Int 17(1): 126-131.

27. Mulasso A, Roppolo M, Giannotta F, Rabaglietti E (2016) Associations of frailty and psychosocial factors with autonomy in daily activities: a cross-sectional study in Italian community-dwelling older adults. Clin Interv Aging 11: 37-45

28. Hansen MC, Flores DV, Coverdale J, Burnett J (2016) Correlates of depression in self-neglecting older adults: A cross-sectional study examining the role of alcohol abuse and pain in increasing vulnerability. J Elder Abuse Negl 28(1): 41-56. 
29. Choi SJ, Chang JS, Kong ID (2015) Effects of a Social Welfare Program for Health Promotion on Cardiovascular Risk Factors. J Lifestyle Med 5 (2): 76-82.

30. Kim T, Nguyen ET, Yuen EJ, Nguyen T, Sorn R, et al. (2015) Differential Role of Social Connectedness in Geriatric Depression Among Southeast Asian Ethnic Groups. Prog Community Health Partnersh 9(4): 483-493.

31. A cura di Ministero della salute (2011) Centrality of Person in the Rehabilitation Process: new organization and management guidelines.

32. Adapted Physical Activity (2016): the Italian National Health Ministry promotes it and dictates its application limits.

33. The National Institute for Health and Care Excellence (NICE) Guidance List (2016)

34. The National Institute for Health and Care Excellence (NICE) Physical activity overview (2016). UK.

35. The National Institute for Health and Care Excellence (NICE) Physical activity: exercise referral schemes. NICE guidelines [PH54] (2014).

36. Centers for Diseases Control and Prevention Division of Nutrition, Physical Activity, and Obesity, National Center for Chronic Disease Prevention and Health Promotion of the U.S. Department of Health \& Human Services (2017).

37. Santos EB, Cuénoud P, Spagnoli J, Junod J (2009) Prevalence of frailty in middle-aged and older community-dwelling Europeans living in 10 countries. J Gerontol A Biol Sci Med Sci 64(6): 675-681.

38. Hogan DB, MacKnight C, Bergman H (2003) Models, definitions, and criteria of frailty . Aging Clin Exp Res (suppl 3) 15: 1 -29.

39. Walston J, Hadley EC, Ferrucci L, et al. (2006) Research agenda for frailty in older adults: towards a better understanding of physiology and etiology: summary from the American Geriatrics Society/National Institute on Aging Research conference on frailty in older adults . J Am Geriatr Soc 54(6): 991-1001.

40. Fried LP, Tangen CM, Walston J, Newman AB, Hirsch C, et al. (2001) Frailty in older adults: evidence for a phenotype. J Gerontol A Biol Sci Med Sci 56(3): M146-M156.

41. Fried LP, Ferrucci L, Darer J, Williamson JD, Andersen G (2004) Untangling the concepts of disability, frailty, and comorbidity: implications for improved targeting and care. J Gerontol A Biol Sci Med Sci 59(3): 255-263.

42. Thompson PD, Buchner D, Pina IL, Balady GJ, Williams MA, (2003) American Heart Association Council on Clinical Cardiology Subcommittee on Exercise, Rehabilitation, and Prevention; American Heart Association Council on Nutrition, Physical Activity, and Metabolism Subcommittee on Physical Activity. Exercise and physical activity in the prevention and treatment of atherosclerotic cardiovascular disease: a statement from the Council on Clinica Cardiology (Subcommittee on Exercise, Rehabilitation, and Prevention) and the Council on Nutrition, Physical Activity, and Metabolism (Subcommittee on Physical Activity). Circulation 107(24): 3109-3116.

43. Titze S, Marti B (1997) [Individually adapted counseling about physical activity in medical practice]. Orthopade 26(11): 935-941. German.

44. Tolomio S, Ermolao A, Travain G, Zaccaria M (2008) Short-term adapted physical activity program improves bone quality in osteopenic/ osteoporotic postmenopausal women. J Phys Act Health 5(6): 844-853.

45. Breuil V (2012) Precautions before starting a treatment for osteoporosis. Rev Prat 62(2): 204-208.

46. Sofi F, Molino LR, Nucida V, Taviani A, Benvenuti F, (2011) Adaptive physical activity and back pain: a non-randomised community-based intervention trial. Eur J Phys Rehabil Med 47(4): 543-549.

47. Benedetti MG, Berti L, Presti C, Frizziero A, Giannini S (2008) Effects of an adapted physical activity program in a group of elderly subjects with flexed posture: clinical and instrumental assessment. J Neuroeng Rehabil 5: 32.

48. Marini M, Sarchielli E, Brogi L, Lazzeri R, Salerno R, (2008) Role of adapted physical activity to prevent the adverse effects of the sarcopenia. A pilot study. Ital J Anat Embryol 113(4): 217-225.

49. Carraro A, Cognolato S, Bernardis AL (1998) Evaluation of a programme of adapted physical activity for ED patients. Eat Weight Disord 3(3): 110-114.

50. Donnard M, Rahmani A, Lorin P, Boyas S, Beaune B (2014) Adapted physical activity intervention and vestibular disorders. Comput Methods Biomech Biomed Engin 17(Suppl 1): 186-187.

51. Seynnes O, Hue O, Ledrole D, Bernard PL (2002) Adapted physical activity in old age: effects of a low-intensity training program on isokinetic power and fatigability. Aging Clin Exp Res 14(6): 491-498.

52. Riddell MC, Burr J (2011) Evidence-based risk assessment and recommendations for physical activity clearance: diabetes mellitus and related comorbidities. Appl Physiol Nutr Metab 36(Suppl 1): S154-S89.

53. Cugusi L, Solla P, Zedda F, Loi M, Serpe R, et al. (2014) Effects of an adapted physical activity program on motor and non-motor functions and quality of life in patients with Parkinson's disease. NeuroRehabilitation 35(4): 789-794.

54. Fragoso YD, Santana DL, Pinto RC (2008) The positive effects of a physical activity program for multiple sclerosis patients with fatigue. NeuroRehabilitation 23(2): 153-157.

55. Taricco M, Dallolio L, Calugi S, Rucci P, Fugazzaro S (2014) Esercizio Fisico di Gruppo/2009 Investigators. Impact of adapted physical activity and therapeutic patient education on functioning and quality of life in patients with postacute strokes. Neurorehabil Neural Repair 28(8): 719-728.

56. Myers J, McAuley P, Lavie CJ, Despres JP, Arena R, et al. (2015) Physical activity and cardiorespiratory fitness as major markers of cardiovascular risk: their independent and interwoven importance to health status. Prog Cardiovasc Dis 57(4): 306-314.

57. Foucaut AM, Berthouze ASE, Touillaud M, Kempf LAS, Baudinet C, et al. (2014) Reduction of health risk factors through an adapted physical activity program in patients with breast cancer. Support Care Cancer 22(4): 1097-1104.

58. Mirandola D, Miccinesi G, Muraca MG, Sgambati E, Monaci M, et al. (2014) Evidence for adapted physical activity as an effective intervention for upper limb mobility and quality of life in breast cancer survivors. J Phys Act Health. 11(4): 814-822.

59. Paolucci T, Vetrano M, Zangrando F, Vulpiani MC, Grasso MR, et al. (2015) MMPI-2 profiles and illness perception in fibromyalgia syndrome: The role of therapeutic exercise as adapted physical activity. J Back Musculoskelet Rehabil 28(1): 101-109.

60. Larun L, Malterud K (2011) Finding the right balance of physical activity: a focus group study about experiences among patients with chronic fatigue syndrome. Patient Educ Couns 83(2): 222-226.

61. Blain H, Vuillemin A, Blain A, Jeandel C (2000) The preventive effects of physical activity in the elderly. Presse Med 29(22): 1240-1248.

62. Conn VS, Minor MA, Burks KJ, Rantz MJ, (2003) Pomeroy SH Integrative review of physical activity intervention research with aging adults. J Am Geriatr Soc 51(8): 1159-1168.

63. Blacklock RE, Rhodes RE, Brown SG (2007) Relationship between regular walking, physical activity, and health-related quality of life. J Phys Act Health 4(2): 138-152.

64. Radasević H, Puljak A, Mihok D, Tomek RS (2007) [Continuous physical activity promotes healthy ageing]. Acta Med Croatica 61(Suppl 1):6973. 
65. Castillo Garzón MJ, Ortega Porcel FB, Ruiz Ruiz J (2005) [Improvement of physical fitness as anti-aging intervention]. Med Clin (Barc) 124(4): 146-55.

66. Reid G (2003) Defining adapted physical activity. In Steadward RD Wheeler GD \& Watkinson EJ (Eds.), Adapted physical activity pp: 704.

67. Macchi C, Benvenuti F (2012) Methodology and Didactics of Adapted Physical Activities-APA [Metodologia e didattica delle attività fisiche adattate (AFA)][Italian] 2nd Ed. Masterbooks (Eds). Firenze ISBN/ EAN: 9788867610105

68. Simons MBG, Pate RR, Simons MDG (1988) Prescribing physical activity to prevent disease. Postgrad Med 83(1): 165-166, 169-72, 175-6.

69. Vuori IM, Lavie CJ, Blair SN (2013) Physical activity promotion in the health care system. Mayo Clin Proc 88(12): 1446-1461.

70. Oja P, Bull FC, Fogelholm M, Martin BW (2010) Physical activity recommendations for health: what should Europe do? BMC Public Health 10: 10

71. Simon C, Chabrier G (2005) How to prescribe physical activity in clinical practice? Ann Endocrinol (Paris) 66(2 Pt 3): S 229-S235.

72. Maddali Bongi S, Del Rosso A (2010) How to prescribe physical exercise in rheumatology. Reumatismo 62(1): 4-11.

73. Windt J, Windt A, Davis J, Petrella R, Khan K (2015) Can a 3-hour educational workshop and the provision of practical tools encourage family physicians to prescribe physical activity as medicine? A pre-post study. BMJ Open. 5(7): e007920.

74. Nella odierna seduta del 10 febbraio (2011) La Conferenza Permenante per I Rapporti Tra Lo Stato, Le Regioni e Le Province Autonome Di Trento e Bolanzo.

75. Wu S, Cohen D, Shi Y, Pearson M, Sturm R (2011) Economic analysis of physical activity interventions. Am J Prev Med 40(2): 149-158.

76. Rocco M (2013) Economical assessment of Adapted Physical Activity for senior dysfunctional citizens [Valutazione economica dell' attività fisica adattata per anziani disabili. University Degree Final Dissertation in Health Economics - Genoa University.

77. Piastra G, Ferrari BM, Lucarini S, Cavagnaro P (2012) Back pain and Adapted Physical Activity: results from the experience in ASL 4 Chiavarese of Liguria. G Gerontol 60: 106-112.

78. Samsoniene L, Adomaitiene R, Kriviciūte J, Jankauskiene K, Jurkstiene $\mathrm{V}$, et al. (2008) [Socialization of athletes with disabilities in adapted physical activity]. Medicina (Kaunas) 44(11): 877-884.

79. Rozzini R, Frisoni GB, Bianchetti A, Zanetti O, Trabucchi M (1993) Physical Performance Test and Activities of Daily Living scales in the assessment of health status in elderly people. J Am Geriatr Soc 41(10) 1109-1113.

80. Padua R, Padua L, Ceccarelli E, Romanini E, Zanoli G, et al. (2002) Italian version of the Roland Disability Questionnaire, specific for low back pain: cross-cultural adaptation and validation. Eur Spine J 11(2): 126-129.
81. Rinaldi P, Mecocci P, Benedetti C, Ercolani S, Bregnocchi M, et al. (2003) Validation of the five-item geriatric depression scale in elderly subjects in three different settings. J Am Geriatr Soc 51(5): 694-698.

82. Delbaere K, Close JC, Mikolaizak AS, Sachdev PS, Brodaty H, et al (2010) The Falls Efficacy Scale International (FES-I). A comprehensive longitudinal validation study. Age Ageing 39(2):210-216.

83. Bower ES, Wetherell JL, Merz CC, Petkus AJ, Malcarne VL, et al. (2015) A new measure of fear of falling: psychometric properties of the fear of falling questionnaire revised (FFQ-R). Int Int Psychogeriatr 27(7): 1121-1133.

84. Richardson MT, Leon AS, Jacobs DR, Ainsworth BE, Serfass R (1994) Comprehensive evaluation of the Minnesota Leisure Time Physical Activity Questionnaire. J Clin Epidemiol 47(3): 271-281.

85. No Authors listed Falls Among Older Adults: An Overview. Centers for Disease Control and Prevention, National Center for Injury Prevention and Control, Division of Unintentional Injury Prevention. Page last updated: 2017

86. Baratto L, Morasso PG, Re C, Spada G (2002) A new look at posturographic analysis in the clinical context: sway-density versus other parameterization techniques. Motor Control 6(3): 246-270.

87. Dalbak LG, Straand J, Melbye H (2015) Should pulse oximetry be included in GPs' assessment of patients with obstructive lung disease? Scand J Prim Health Care 33(4): 305-310.

88. Elaine Fess (2011) Functional Tests (Chapter 12) In. Skirven TM, Osterman AL, Fedorcsyk JM, Amadio PC, (Eds) (Chapter 12) Rehabilitation of the Hand and Upper Extremity. (6th edn) Philadelphia, PA: Elsevier.

89. Peters MJ, Van NSI, Vanhoutte EK, Bakkers M, Van DPA, et al (2011) Revised normative values for grip strength with the Jamar dynamometer. J Peripher Nerv Syst 16(1): 47-50.

90. Takazawa K, Tanaka N, Fujita M, Matsuoka O, Saiki T, et al. (1998) Assessment of vasoactive agents and vascular aging by the second derivative of photoplethysmogram waveform. Hypertension 32(2): 365-370.

91. Elgendi M (2012) On the analysis of fingertip photoplethysmogram signals. Curr Cardiol Rev 8(1): 14-25.

92. Kyle UG, Bosaeus I, De Lorenzo AD, Deurenberg P, Elia M, et al. (2004) Composition of the ESPEN Working Group. Bioelectrical impedance analysis-part I: review of principles and methods. Clin Nutr 23(5): 1226-1243.

93. Kyle UG, Bosaeus I, De Lorenzo AD, Deurenberg P, Elia M, et al. (2004) Bioelectrical impedance analysis-part II: utilization in clinical practice. Clin Nutr 23(6): 1430-1453.

94. Tessler LS, McDade TW (2008) 13 Minimally Invasive and Innovative Methods for Biomeasure Collection in: Population-Based Research. National Research Council (US) Committee on Advances in Collecting and Utilizing Biological Indicators and Genetic Information in Social Science Surveys; Weinstein M, Vaupel JW, Wachter KW, (Eds.), Biosocial Surveys. Washington (DC): NationalAcademiePress(US) 
CC (i) This work is licensed under Creative BY DOI: 10.19080/JYP.2017.01.555562
Your next submission with Juniper Publishers will reach you the below assets

- Quality Editorial service

- Swift Peer Review

- Reprints availability

- E-prints Service

- Manuscript Podcast for convenient understanding

- Global attainment for your research

- Manuscript accessibility in different formats ( Pdf, E-pub, Full Text, Audio)

- Unceasing customer service

Track the below URL for one-step submission https://juniperpublishers.com/online-submission.php 